\title{
Cytogenetic comparison of Podocnemis expansa and Podocnemis unifilis: A case of inversion and duplication involving constitutive heterochromatin
}

\author{
Ricardo José Gunski ${ }^{1}$, Isabel Souza Cunha ${ }^{2}$, Tiago Marafiga Degrandi ${ }^{1}$, Mario Ledesma ${ }^{3}$ \\ and Analía Del Valle Garnero ${ }^{1}$ \\ ${ }^{1}$ Universidade Federal do Pampa, Campus São Gabriel, São Gabriel, RS, Brazil. \\ ${ }^{2}$ Secretaria Municipal de Meio Ambiente e Turismo, São Desidério, BA, Brazil. \\ ${ }^{3}$ Parque Ecológico "El Puma", Candelaria, Argentina.
}

\begin{abstract}
Podocnemis expansa and $P$. unifilis present $2 n=28$ chromosomes, a diploid number similar to those observed in other species of the genus. The aim of this study was to characterize these two species using conventional staining and differential CBG-, GTG and Ag-NOR banding. We analyzed specimens of $P$. expansa and $P$. unifilis from the state of Tocantins (Brazil), in which we found a $2 n=28$ and karyotypes differing in the morphology of the $13^{\text {th }}$ pair, which was submetacentric in $P$. expansa and telocentric in $P$. unifilis. The CBG-banding patterns revealed a heterochromatic block in the short arm of pair 13 of $P$. expansa and an interstitial one in pair 13 of $P$. unifilis, suggesting a pericentric inversion. Pair 14 of $P$. unifilis showed an insterstitial band in the long arm that was absent in $P$. expansa, suggesting a duplication in this region. Ag-NORs were observed in the first chromosome pair of both species and was associated to a secondary constriction and heterochromatic blocks.
\end{abstract}

Keywords: chromosome banding, Ag-NORs, karyotype, chelonids.

Received: December 6, 2012; Accepted: March 12, 2013.

Cytogenetic studies on species of the order Testudines are very scarce when compared to other orders of the class Reptilia (Barros et al., 1976). According to Ezaz et al. (2006), there is karyotypic information on approximately 150 species belonging to twelve families (Cheloniidae, Chelydridae, Emydidae, Kinosternidae, Testudinidae, Trionychidae, Carettochelyidae, Chelidae, Podocnemididae, Pelomedusidae, Dermochelyidae and Dermatemydidae).

There are currently three recognized karyotypic groups defined for the order Testudines: I) karyotypes with high diploid numbers, $2 n=60$ to 64 chromosomes, with the presence of microchromosomes; II) karyotypes with diploid numbers ranging from $2 \mathrm{n}=50$ to 56 chromosomes and with less microchromosomes than in the first group; III) karyotypes with low diploid numbers, ranging from $2 \mathrm{n}=26$ to 28 chromosomes, and without microchromosomes (Ayres et al., 1969; Barros et al., 1976; Bull and Legler, 1980; Bickham et al., 1985).

The Podocnemididae family consists of three genera (Erymnochelys, Peltocephalus and Podocnemis) distributed through Madagascar and South America (Noonan,

Send correspondence to Ricardo José Gunski. Universidade Federal do Pampa, Campus São Gabriel, Av. Antônio Trilha 1847, 97300-000 São Gabriel, RS, Brazil. E-mail: rgunski@yahoo.com.br.
2000). According to Ramírez et al. (2008), the genus Podocnemis includes six species ( $P$. expansa, $P$. vogli, $P$. sextuberculata, $P$. unifilis, $P$. lewyana, P. erythrocephala), which have diverged in this sequence according to molecular phylogenetic data. Cytogenetic studies in Podocnemis have revealed that species of this genus present the same diploid number of $2 \mathrm{n}=28$ (Rhodin et al., 1978, Ortiz et al., 2005, Fantin and Monjeló, 2011).

Huang and Clark (1969) described the karyotypes of $P$. expansa and $P$. unifilis, which were characterized by a comparatively low diploid number, the lack of microchromosomes and of sex chromosomes and by the presence of several secondary constrictions. The aim of this study was to perform cytogenetic analyses of Podocnemis expansa and $P$. unifilis, using conventional staining and CBG-, GTG- and Ag-NORs banding patterns.

The samples were obtained from six specimens of $P$. expansa from the Experimental Station of the Universidade Federal do Tocantins - UFT (Palmas-TO) (IBAMA license number 028/05-RAN), and seven fertilized eggs of $P$. unifilis from the Tocantins River in the municipality of Ipueiras-TO.

Metaphase preparations were obtained from the peripheral blood of $P$. expansa (Moorhead et al., 1960) and from fertilized eggs of $P$. unifilis (De Boer, 1984). CBG-, GTG- and Ag-NORs banding were performed according to 
Sumner (1972), Seabright (1971) and Howell and Black (1980), respectively.

An average of 40 metaphases per sample were analyzed after conventional Giemsa,staining and photographs were used to mount the karyotypes. This was followed by sequential analysis of CBG- and Ag-NORs banding.

The P. expansa (Figure 1a) and P. unifilis (Figure 1b) specimens presented $2 \mathrm{n}=28$ chromosomes and fundamental numbers of $\mathrm{FN}=54$ and 52, respectively. The karyotypes were mounted according to Rhodin et al. (1978) and the chromosomes were divided into morphological groups to allow a better comparison between the species.

Pairs 1, 2 and 3, the largest metacentrics, were similar between the two species. Pair 4 was an acrocentric with a visible short arm, pairs 5 to 12 were metacentric, and pair 14 was telocentric. The only difference between the karyotypes of the two species was pair 13, which was telocentric in $P$. unifilis and a small submetacentric in P. expansa.

After CBG-banding, $P$. expansa (Figure $2 \mathrm{a}$ and $2 \mathrm{~b}$ ) presented a faint staining in the centromeric regions. In $P$. unifilis, strong staining was present in the centromeric regions of most chromosomes and in the secondary constrictions of pairs 13 and 14 (Figure 2c and 2d).

A positive CBG- band was present in the short arm of the metacentric pair 13 of $P$. expansa, whereas a positive interstitial band was observed in the long arm of the telocentric chromosome 13 in P. unifilis. These observations suggest that a pericentric inversion that did not affect the heterochromatin may be responsible for the morphological difference of pair 13 between both species.

Pair 14, which is telocentric in both species, presented a heterochromatic block in its secondary constriction in P. unifilis, which was absent in $P$. expansa, suggesting the occurrence of a heterochromatin duplication in the long arm of the first species.

GTG-banding was used to individually identify the chromosomes and to look for chromosome rearrangements between the species (Figure 2e). This comparison confirmed the divergence observed after CBG-banding in pair
14: two dark bands and one light interstitial band were present in P.unifilis, whereas one light band in the centromeric region and one dark telomeric band were evidenced in $P$. expansa, confirming the duplication.

The Ag-NORs were located in an interstitial position associated with a secondary constriction in pair 1 (Figure 3) of both species, co-localized with a positive CBG-band. The coincidence of staining with both techniques could be related to the presence of proteins in this region that would make it less sensitive to the acidic treatment used during CBG-banding.

The diploid number of $2 \mathrm{n}=28$ and the fundamental numbers $\mathrm{FN}=52$ and $\mathrm{FN}=54$, observed in $P$. unifilis and $P$. expansa, respectively, are in agreement with the diploid numbers described by Ayres et al. (1969) and Huang and Clark (1969). The morphological divergence in pair 13 telocentric in $P$. unifilis and submetacentric in $P$. expansa is the main distinctive characteristic between both species.

This is the first report of the CBG-banding patterns of $P$. expansa and $P$. unifilis, which showed predominantly centromeric bands, whereas in $P$. vogli the heterochromatin was interstitial and telomeric (Ortiz et al., 2005).

The sequential analysis of the same metaphases using conventional Giemsa staining and CBG-banding was efficient for comparing and identifying chromosome differences between the karyotypes of the two Podocnemis species. We were able to confirm an inversion in pair 13 and a duplication in pair 14 of $P$. unifilis, through the observation of constitutive heterochromatin associated with secondary constrictions.

The secondary constriction in the short arm of pair 1 of both species was the site of the nucleolus organizer region (NOR). This is in accordance with the results of Fantin and Monjeló (2011) and suggests a significant similarity to the single NOR-bearing chromosome identified in $P$. sextuberculata and $P$. vogli (Ortiz et al., 2005).

Species in the genus Podocnemis are characterized by low diploid numbers $(2 \mathrm{n}=26$ and 28) and the absence of microchromosomes and sex chromosomes, whereas in a)

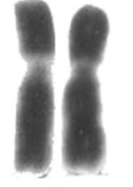

1

b)

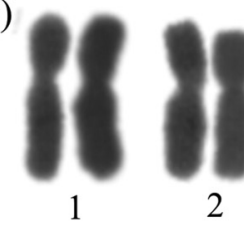

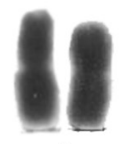

3

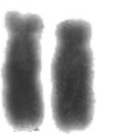

4

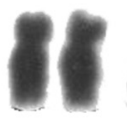

5

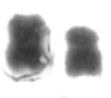

6
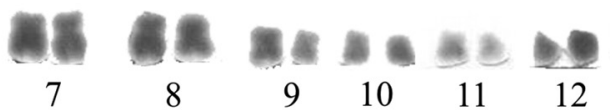

12

13

14

Figure 1 - Karyotypes of $P$. expansa (a) and $P$. unifilis (b). Both species presented $2 \mathrm{n}=28$ and $\mathrm{FN}=54$ and 52 , respectively, due to differences in pair 13 : submetacentric (a) and telocentric (b). 
a)
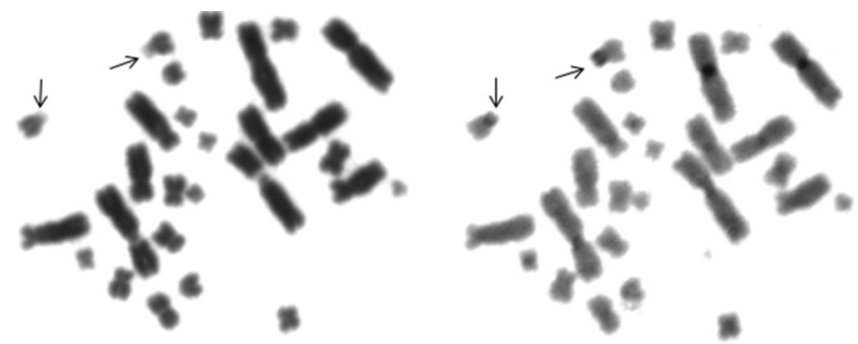

b)

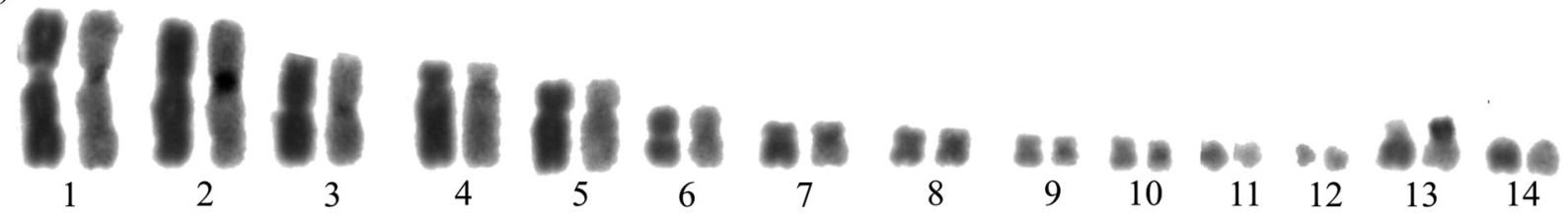

c)
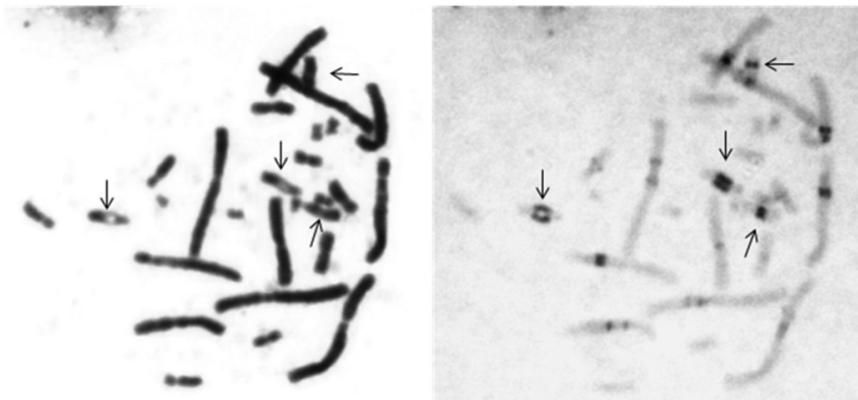

d)

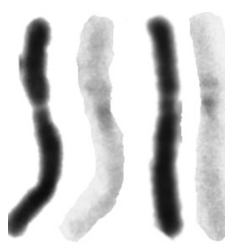

1

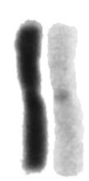

3

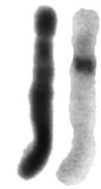

4
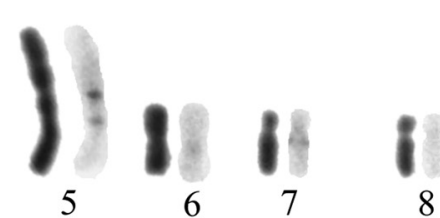

8

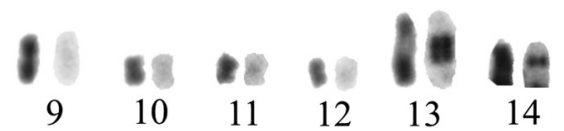

e)

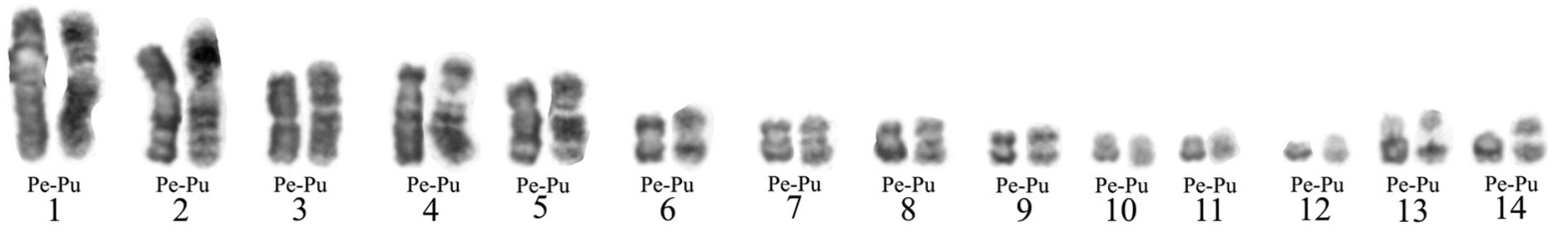

Figure 2 - Sequential analysis of Giemsa stained and CBG-banded metaphases and karyotype of P. expansa $(\mathrm{a}, \mathrm{b})$ and $P$. unifilis (c, d). Arrows show the CBG-bands on the short arm of pair 13 (a) and on the secondary constrictions of pairs 13 and 14 (c). (e) GTG-banded chromosomes of $P$. expansa (Pe) and P. unifilis $(\mathrm{Pu})$.

a)

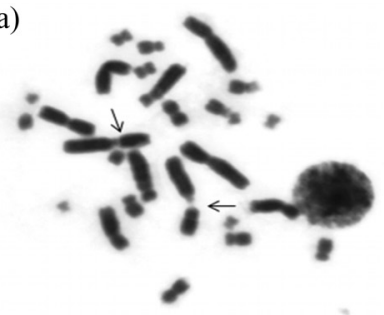

b)

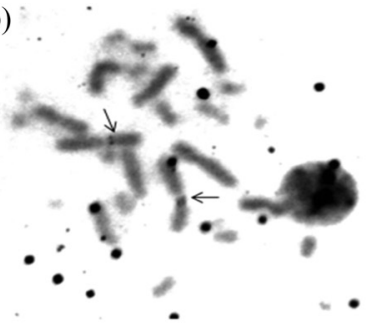

c)

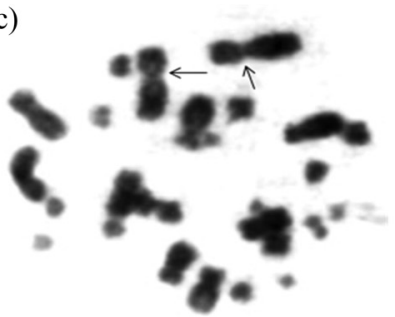

d)

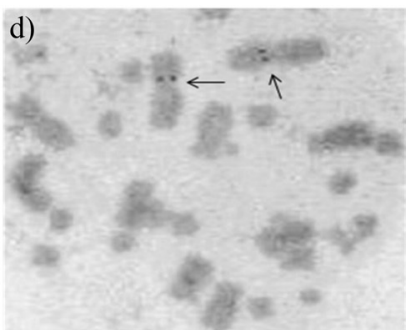

Figure 3 - Sequential Giemsa staining and Ag NOR of P. expansa $(\mathrm{a}, \mathrm{b})$ and $P$. unifilis $(\mathrm{c}, \mathrm{d})$ : Arrows show the nucleolus organizer regions located in secondary constriction of pair 1. 
Platemys platycephala, Bull and Legler (1980) and Bickham et al. (1985) found $2 \mathrm{n}=96$ and the presence of microchromosomes. Thus, multiple chromosome rearrangements may be responsible for the reduction in diploid numbers in this genus, as suggested by Fantin and Monjeló (2011).

CBG- and GTG-banding should be included in the studies of other species of this genus, since they would add information on chromosome rearrangements that could be present without resulting in morphological variation.

\section{Acknowledgments}

We would like to thank NATURATINS and the Experimental Station of the Universidade Federal do Tocantins for the valuable support and logistics needed to fulfill this study.

\section{References}

Ayres M, Sampaio MM, Barros RMS, Dias LB and Cunha OR (1969) A karyological study of turtles from the Brazilian Amazon region. Cytogenetics 8:401-409.

Barros RM, Sampaio MM, Assis MF and Ayres M (1976) General considerations on the karyotypic evolution of Chelonia from the Amazon region of Brazil. Cytologia 41:559-565.

Bickham JW, Tucker PK and Legler JM (1985) Diploid-triploid mosaicism: An unusual phenomenon in side-necked turtles (Platemys platycephala). Science 227:1591-1593.

Bull JJ and Legler JM (1980) Karyotypes of sidenecked turtles (Testudines, Pleurodira). Can J Zool 58:828-841.

De Boer LEM (1984) New developments in vertebrate cytotaxonomy. VIII. A current list of references on avian karyology. Genetica 65:3-37.

Ezaz T, Valenzuela N, Grützner F, Miura I, Georges A, Burke RL and Graves JAM (2006) An XX/XY sex microchromosome system in a freshwater turtle, Chelodina longicollis (Tes- tudines, Chelidae) with genetic sex determination. Chromosome Res 14:139-150.

Fantin C and Monjeló LAS (2011) Cytogenetic studies in Podocnemis expansa and Podocnemis sextuberculata (Testudines, Podocnemididae), turtles of the Brazilian Amazon. Caryologia 64:154-157.

Howell WR and Black DA (1980) Controlled silver staining of nucleolus organizer regions with a protective colloidal developer: A 1 - step method. Experientia 36:1014-1015.

Huang CC and Clark NP. (1969) Chromosome studies of the cultured cells of two species of side-necked turtles (Podocnemis unifilis and Podocnemis expansa). Chromosoma 26:245-253.

Moorhead RS, Howel PC, Mellman WJ, Battips DM and Hundgerford DA (1960) Chromosome preparations of leukocytes cultured from human peripheral blood. Exp Cell Res 2:613-616.

Noonan BP (2000) Does the phylogeny of the Pelomedusidae turtle reflect vicariance to continental drift. J Biogeogr 27:1245-1249.

Ortiz ML, Rodríguez PA and Bueno ML (2005). Caracterización citogenética de la tortuga sabanera Podocnemis vogli (Reptilia, Testudinata, Podocnemididae). Acta Biol Colomb 10:19-33.

Ramírez MV, Mora OVC and Fritz U (2008) Molecular phylogeny and divergence times of ancient South American and Malagasy river turtles (Testudines, Pleurodira, Podocnemididae). Organisms Divers Evol 8:388-398.

Rhodin AJ, Mittermeier AL, Gardner AL and Medem F (1978) Karyotypic analysis of the Podocnemis turtles. Copeia 1978:723-728.

Sumner AT (1972) A simple technique for demonstrating centromeric heterochromatin. Exp Cell Res 75:304-306.

Seabright M (1971) A rapid banding technique for human chromosomes. Lancet 2:971-972.

Associate Editor: Yatiyo Yonenaga-Yassuda

License information: This is an open-access article distributed under the terms of the Creative Commons Attribution License, which permits unrestricted use, distribution, and reproduction in any medium, provided the original work is properly cited. 